This is the author's final, peer-reviewed manuscript as accepted for publication. The publisher-formatted version may be available through the publisher's web site or your institution's library.

\title{
Identification of equine herpes virus 5 in horses with lymphoma
}

Karie A. Vander Werf, Elizabeth G. Davis, Kyathanahalli Janardhan, Bhupinder Bawa, Steve Bolin, Kelli Almes

\section{How to cite this manuscript}

If you make reference to this version of the manuscript, use the following information:

Vander Werf, K. A., Davis, E. G., Janardhan, K., Bawa, B., Bolin, S., \& Almes, K. (2014). Identification of equine herpes virus 5 in horses with lymphoma. Retrieved from http://krex.ksu.edu

\section{Published Version Information}

Citation: Vander Werf, K. A., Davis, E. G., Janardhan, K., Bawa, B., Bolin, S., \& Almes, K. (2014). Identification of equine herpesvirus 5 in horses with lymphoma. Journal of Equine Veterinary Science, 34(6), 738-741.

Copyright: (c) 2014 Elsevier Inc.

Digital Object Identifier (DOI): doi:10.1016/j.jevs.2013.12.017

Publisher's Link: http://www.sciencedirect.com/science/article/pii/S0737080613009660

This item was retrieved from the K-State Research Exchange (K-REx), the institutional repository of Kansas State University. K-REx is available at http://krex.ksu.edu 


\section{Identification of equine herpes virus 5 in horses with lymphoma}

Karie A. Vander Werf, DVM, MS ${ }^{1}$

Elizabeth G. Davis, DVM, PhD, DACVIM ${ }^{1}$

Kyathanahalli Janardhan, MVSc, PhD, DACVP ${ }^{2}$

Bhupinder Bawa, DVM, PhD, DACVP²

Steve Bolin, DVM, MS, $\mathrm{PhD}^{3}$

Kelli Almes, DVM, DACVP²

Affiliations:

${ }^{1}$ Department of Clinical Sciences, College of Veterinary Medicine, Kansas State University, Manattan, KS 66506 (Vander Werf, Davis)

${ }^{2}$ Department of Diagnostic Medicine/Pathobiology, College of Veterinary Medicine, Kansas State University, Manhattan, KS, 66506 (Janardhan, Bawa, Almes)

${ }^{3}$ Department of Pathobiology and Diagnostic Investigation, College of Veterinary Medicine, Michigan State University, East Lansing, MI 48824 (Williams, Bolin)

Address correspondence to kvanderw@illinois.edu

Keywords: oncology, gamma herpesvirus, lymphoma, equine, virology

\section{Abbreviations:}

EMPF: Equine multinodular pulmonary fibrosis

EHV: Equine herpesvirus

HHV-4, -8: Human herpesvirus 4, 8

PCR: Polymerase chain reaction 
PBS: Phosphate buffered solution

Where the work was done: Kansas State University, Michigan State University

Whether the study was supported by a grant or otherwise: KSU Small Research Grant

Meeting, if any, at which the paper was presented: Poster abstract at ACVIM 2011. 


\section{Abstract}

Equine multinodular pulmonary fibrosis, equine herpesvirus 5, and multicentric lymphoma were discovered in one patient. Review of gamma herpesvirus activity in humans revealed a propensity for lymphoproliferative disorders associated with infection. The objective was to determine the frequency of equine herpesvirus 5 in lymphoma tissues and compare with the frequency found in the lymph nodes of clinically normal horses. Case control investigation of lymphoma positive tissues and analysis via PCR for EHV-5 was performed on 12 horses. Prospective collection and PCR analysis of lymph nodes (mesenteric or submandibular) for EHV5 was performed on 21 control horses. Thirteen samples of lymphoma positive tissues and fluid were submitted for PCR analysis for EHV-5. Of these, $67 \%$ were positive. In the control horse population, $14 \%$ were positive for EHV-5 $(p=0.004)$. Neoplastic samples positive for EHV-5 were classified as T-cell rich B-cell lymphoma (3), T-cell lymphoma (1), 1 was non-differentiated, and 2 were not stained. Gamma herpesviruses in humans have been associated with lymphoproliferative diseases such as Kaposi's sarcoma and Burkitt's lymphoma. This study reveals an increased frequency of equine herpesvirus 5 (gamma herpesvirus) in horses diagnosed with lymphoma compared to healthy control horses. Although the exact role this virus plays in the initiation or perpetuation of lymphoproliferative neoplasia is unknown, EHV-5 may be an etiologic agent associated with the development of some types of equine Iymphoma.

\subsection{Introduction}


Equine lymphoma is a devastating, fatal disease that may affect horses of all ages. To date, there is no known infectious etiologic agent. A horse that presented to the Veterinary Health Center at Kansas State University was diagnosed with both multicentric Iymphoma and Equine Multinodular Pulmonary Fibrosis (EMPF) and was positive on polymerase chain reaction (PCR) on pulmonary tissues and lymph node (Horse 1, Table 1) for equine herpesvirus 5 (EHV-5), a gamma herpesvirus, which has been recently associated with EMPF [1]. Additionally, a horse with T-cell leukemia and EMPF, also positive for EHV-5 on PCR analysis of lung, lymph node, and bone marrow, was recently reported [2]. In humans, gamma herpesviruses, such as Epstein Barr Virus and Kaposi's Sarcoma-associated Herpes Virus, have been associated with malignant and non-malignant lymphoproliferative conditions such as Burkitt's lymphoma, Multicentric Castleman's Disease, and Kaposi's Sarcoma $[3,4,5]$. Therefore, it was the aim of our study to evaluate the frequency of EHV-5 in lymphoma cases compared to normal, healthy control cases.

\subsection{Materials and Methods}

\subsubsection{Study Design and Samples}

A retrospective review of patient records of horses presenting to the University from 2005 to 2010 was performed to identify those with a histopathologic diagnosis of lymphoma. Additionally, all cases with a positive diagnosis of lymphoma presenting in 2010 and 2011 were prospectively selected, including one case from Kentucky and one case from Illinois. Diagnosis of lymphoma was made either ante- or post mortem with biopsy and/or histopathology of 
neoplastic lymph nodes or tissues. Information gathered from records included signalment, site of lymphoma, and immunophenotype of neoplastic cells if performed.

Sample size was determined using the following assumptions: an alpha $=0.05$, a power $=0.8$, and an expected difference in EHV-5 status between lymphoma and control animals of at least $40 \%$ (lymphoma $>60 \%$, control animals $<20 \%$ ). Twenty one control horses, presented to the KSU VHC for euthanasia for reasons other than respiratory disease or lymphoma, were sequentially sampled and one lymphoid tissue (either submandibular or mesenteric) was submitted for PCR analysis after storage at $-80^{\circ} \mathrm{C}$. Gross post mortem examination was performed on control horses to ensure that overt respiratory or lymphoproliferative disease was not present. Lymphoid tissue was specifically isolated for EHV-5 PCR testing in control horses due to the propensity that this virus has for lymphocytes which are localized to this tissue type.

\subsubsection{DNA Extraction and PCR Assays}

The methods used for DNA extraction were dependent on the sample available for testing. The neoplastic tissues from 12 horses were either formalin fixed or formalin fixed and paraffin embedded. To remove formalin, the formalin fixed tissues not embedded in paraffin were soaked in phosphate buffered saline (PBS) solution at $4^{\circ} \mathrm{C}$ for 2 days with an exchange of PBS twice a day. The tissues were then minced with a razor blade, suspended in 3 to $4 \mathrm{~mL}$ of Bovarnick's buffer, placed in a $15 \mathrm{~mL}$ conical centrifuge tube containing 5 to 7 copper coated ball bearings ( $4.5 \mathrm{~mm}$ in diameter), and vortexed at full power for 1 minute. A $200 \mu \mathrm{L}$ aliquot 
was removed and added to a $1.5 \mathrm{~mL}$ microcentrifuge tube containing $20 \mu \mathrm{L}$ of proteinase $\mathrm{K}^{\mathrm{a}}$ and incubated at $55^{\circ} \mathrm{C}$ overnight. The remaining steps of DNA extraction were as recommended by the DNA extraction kit manufacturer ${ }^{b}$. For formalin fixed, paraffin embedded tissues, the DNA was extracted as described previously [1].

Cells were pelleted from pleural fluid from 1 horse by centrifugation at $1700 \mathrm{rcf}$ for 10 minutes. The pleural fluid was decanted and the cell pellet was suspended in $200 \mu \mathrm{L}$ of PBS. The DNA was extracted from $30 \mu \mathrm{L}$ of cell suspension using a rapid alkaline polyethylene glycolbased method that allowed direct PCR. For frozen tissues from the control horses, the DNA was extracted as recommended by the DNA extraction kit manufacturer ${ }^{\mathrm{b}}$.

The PCR assays used were gel based and specifically targeted the glycoprotein $(\mathrm{g}) \mathrm{H}$ gene or the gB gene of EHV 5. The analytical sensitivity for both PCR assays was $10^{-1}$ cell culture infectious doses of EHV 5. The PCR primers used to detect the gH gene and the reaction conditions used were previously reported $[1,6]$. That PCR assay produced an amplicon of 344 base pairs and was used for detection of viral DNA in fresh tissues.

The PCR assay used to detect the gB gene of EHV 5 was used for fresh and formalin fixed tissues and was designed from aligned sequences of the gB gene found in public data bases or derived in house. The nucleic acid sequence for the forward primer was TGATATGACGGCCAGATCACAC and CCAACCCCACACCATAGTCT for the reverse primer. Those PCR primers produce an amplicon that is 155 base pairs in length. The reaction conditions were 1 cycle at $94^{\circ} \mathrm{C}, 4 \mathrm{~m} ; 10$ cycles at $95^{\circ} \mathrm{C}, 30 \mathrm{~s}, 67^{\circ} \mathrm{C}$ for cycle 1 then minus $1^{\circ} \mathrm{C} / \mathrm{cycle}, 20 \mathrm{~s}, 72^{\circ}$ C, $60 \mathrm{~s} ; 40$ cycles at $95^{\circ} \mathrm{C}, 30 \mathrm{~s}, 57^{\circ} \mathrm{C}, 20 \mathrm{~s}, 72 \mathrm{C}, 60 \mathrm{~s} ; 1$ cycle at $72^{\circ} \mathrm{C}, 7 \mathrm{~m}$. The same 
commercially available reagent mixture was used for both PCR assays ${ }^{c}$. Nucleic acid sequencing of amplicons from both PCR assays has been done, using diagnostic samples and experimentally derived samples, to verify detection of EHV 5.

\subsubsection{Immunohistochemistry}

Immunohistochemical staining was performed on lymphoma positive tissues using antiCD3 (T cell), -CD79 $\alpha$ (B cell), and/or -CD20 (B cell) antibodies. Because this was a retrospective clinical study, only samples submitted for histology in lymphoma cases were analyzed. Except for Horse 12 , this resulted in one sample per horse.

\subsubsection{Statistical analysis}

A one-sided Fisher exact test was used to determine if there was an association between EHV-5 PCR status and lymphoma status. An odds ratio was also performed to determine the strength of an association if it was found to be significant. A $p<0.05$ was used to determine statistical significance. MedCalc 12.2.1 (Mariakerke, Belgium) was used to analyze the data.

\subsection{Results}

Twelve cases of lymphoma were identified through review of patient records and prospective recruitment. Mean age was $11.25 \pm 6.88$ years. There were 5 mares, 5 geldings, and 2 stallions. Breeds identified included Quarter Horse (4), Paint (2), Thoroughbred (2), Warmblood, Arabian, Clydesdale, and Morgan and were representative of the hospital population. The paraffin-embedded (4) and formalin-fixed (8) histopathology samples that were submitted for PCR analysis included submandibular and thoracic lymph nodes, fibrotic 
lung tissue, a subcutaneous mass, a thoracic mass, and a skin biopsy. Additionally, a sample of pleural fluid obtained ante mortem from Horse 12 was submitted for PCR analysis. Type of lymphoma, immunohistochemical staining results, and results of the PCR analysis are presented in Table 1. Eight lymphoma positive tissues were positive for EHV-5 (67\%).

The mean age of the control horses was $13.6 \pm 7.67$ years and this was not significantly different from case cohorts $(p=0.4)$. There were 13 mares and 8 geldings. Breeds included in the control population included Quarter Horse (13), Thoroughbred (4), Arabian, Paint, Morgan, and Percheron. Reasons for euthanasia were identified as colic (7), donation due to chronic illness, neurologic condition, or lameness (9), catastrophic musculoskeletal injury (3), old age (1), and neurologic disease (1). Three control horses were positive for EHV-5 (14\%). There was a significant difference between the number of positive EHV-5 samples in the lymphoma group compared to the number of positive samples in the control group $(p=0.004)$. The odds of a horse with lymphoma testing positive for EHV-5 was 12 times greater than a healthy horse without lymphoma (95\% Cl: 2.16-66.56).

\subsection{Discussion}

Of the lymphoproliferative disorders encountered in horses, lymphoma is most common, with an overall incidence of approximately $1.3-2.8 \%$ of all equine tumors and a prevalence of $0.002-0.5 \%$ in the equine population $[7,8]$. There is no gender, breed, or age predilection and etiologies have only been speculated but not conclusively determined $[9,10$, 11]. Lymphoma is classified into multicentric, alimentary, mediastinal, cutaneous, and solitary tumors of extranodal sites. Immunohistochemistry is a sensitive and versatile method widely 
used to investigate the antigenic determinants on cells that can lead to more reliable interpretation of neoplastic versus reactive proliferations of lymphocytes and non-lymphoid disorders. Three of the samples included in this study were classified as T-cell rich large B-cell origin, where the B-cells are considered malignant and the T-cells are in high concentration but are benign in character. T-cell lymphoma is overall a more common finding in equine patients with lymphoma [12]; however, this was not reflected in this small subset of cases. Gamma herpesviruses tend to infect and proliferate in either B-cells, such as with Epstein Barr Virus [13, 14, 15] or T-cells, such as with herpesvirus saimiri 2 [16]. Due to the small number of cases that had typing performed and the variety of lymphoma types present in the study, it cannot be determined which lymphoid cells the equine herpesviruses tend to infiltrate. While the majority of gamma herpesviruses are not tumorigenic, some are associated with lymphoproliferative diseases that result in cancerous growths in either their natural host or in a phylogenetically related host. The virus genome replicates in lymphoblastoid cells, but infection is frequently not productive. Two samples remain undifferentiated. This could be due to CD79a and CD20 stain uptake variability in the equine lymphocyte.

Human gamma herpesviruses, such as human herpesvirus 4 (Epstein Barr Virus, EBV) and 8 (Kaposi's Sarcoma-associated herpesvirus, KSHV) (HHV-4, -8), have been positively associated with lymphoproliferative disorders such as Burkitt's lymphoma, Kaposi's Sarcoma, and Primary Effusion Lymphoma. The horse is the natural host of five recognized herpes viruses: EHV-1 (alpha herpesvirus), EHV-2 (gamma), EHV-3 (alpha), EHV-4 (alpha), and EHV-5 (gamma). EHV-5 was first isolated in Australia in 1987 [17] and its prevalence in the equine 
population is variable depending on the specific geographical region tested, ranging from $3 \%$ in respiratory liquids (bronchoalveolar lavage or transtracheal wash) of horses in France [18] to $64 \%$ in nasal secretions in horses in California [19]. In addition, lower prevalence rates have been found in older versus younger horses [20]. There are no data on the prevalence of EHV-5 in other tissues in horses. Although EHV-5 has recently been found to be associated with equine multinodular pulmonary fibrosis (EMPF) [1] and there have been an increasing number of reported cases of EHV-5-associated fibrotic lung diseases, there has only been one report of lymphoproliferative disease associated with EMPF [2]. It is unknown why some horses develop EMPF, some develop lymphoma, and some have no evidence of disease at all but still harbor the latent virus. The same is true for humans who are infected with latent herpesviruses and may or may not develop lymphoproliferative disorders.

Limitations of this study are reflected in its partially retrospective nature. The availability of samples to be evaluated by PCR analysis was limited by the number of samples initially submitted for histopathology when the case presented or was submitted for post mortem examination. Since this was usually limited to one sample, the control and prospective samples were collected and analyzed in the same manner. We were only able to recruit 12 Iymphoma positive animals; however, the sample size was sufficient to detect a difference, thus ruling out the risk of a type II error and we were able to conclude, post-hoc, that our power was sufficient. It is notable that among the lymphoma positive cases there were 12 samples where DNA was extracted from formalin fixed or formalin fixed and paraffin embedded samples. Among these samples there were 7 that were positive for EHV-5. As a result of DNA extraction 
methodology, test sensitivity was reduced, therefore it would be appropriate to consider that the actual number of positive cases may have actually exceeded the reported $64 \%$.

Investigation into the association of EHV-5 and equine lymphoma may lead to further treatment options, including long-term antiviral therapy. Two recent case reports [21, 22] of human patients with Primary Effusion Lymphoma (associated with HHV-8) that were unresponsive to traditional intensive chemotherapy were finally moved to remission with antiviral therapy. With the discovery of a positive association between EHV-5 and equine lymphoma, the response to potential antiviral therapies can be investigated. This theory led to attempted treatment in one horse (Horse 7), first by complete removal of the lymphomatous lymph node chain (submandibular lymph nodes) and chemotherapy for one month. This resulted in a change in cell type from T-cell rich, B-cell to T-cell lymphoma. Acyclovir was then administered for 4 months [23]. Cytology and histopathology revealed complete remission of the lymphoma [24].

In conclusion, EHV-5 has been found more frequently in lymphoma tissues as compared to control lymph nodes in this population. Additional study is required to determine if this frequency is influenced by region. Quantitative PCR may also allow detection of the level of target DNA in the tissues. Further investigation is also required to determine the in vitro sensitivity of EHV-5 to anti-viral agents.

1.5 Acknowledgments: We would like to thank the Shrader family for their generous donation of funds for this investigation. Thank you to Dr Mark Mitchell for statistical assistance and to Dr 
Kurt Williams for assistance with EHV-5 testing. Partial funding was also supplied by a Kansas State University Small Research Grant.

\subsection{Footnotes}
a. Qiagen, Valencia, CA
b. Purification of DNA from Animal Tissues, DNeasy Tissue handbook, Qiagen, Valencia, CA
c. Promega GoTaq Green, Promega, Madison, WI

\subsection{References}

[1] Williams KJ, Maes R, Del Piero F, Lim A, Wise A, et al. Equine multinodular pulmonary fibrosis: a newly recognized herpesvirus-associated fibrotic lung disease. Vet Pathol 2007;44(6):849-862.

[2] Schwarz B, Gruber A, Benetka V, Rutgen B, Schwendenwein I, et al. Concurrent T-cell leukemia and equine multinodular pulmonary fibrosis in a Hanoverian Warmblood mare. Equine Vet Educ 2012;24(4):187-192.

[3] Geraminejad MD, Memar O, Aronson I, Rady PL, Hengge U, et al. Kaposi's sarcoma and other manifestations of human herpesvirus 8. J Am Acad Dermatol 2002;47(5):641-655. 
[4] Boshoff C, et al. Kaposi's sarcoma-associated herpesvirus: a new DNA tumor virus. Annu Rev Med 2001;52:453-470.

[5] Burkitt DP. Etiology of Burkitt's lymphoma - an alternative hypothesis to a vectored virus. J Natl Cancer Inst 1969;42:19-28.

[6] Nordengrahn A, Merza M, Ros C, Lindholmc A, Palfl V, Hannant D, Belak S: Prevalence of equine herpesvirus types 2 and 5 in horse populations by using type-specific PCR assays. Vet Res 2007;33:251-259.

[7] Savage CJ. Lymphoproliferative and myeloproliferative disorders. Vet Clin North Am Equine Pract 1998 Dec;14(3):563-78.

[8] Schneider, D. Lymphoproliferative and myeloproliferative disorders. In: Current Therapy in Equine Medicine, 5th edn., Ed: N.Robinson, Saunders, St. Louis; 2003, pp 359-362.

[9] Detilleux PG, Cheville NF, Sheahan BJ. Ultrastructure and lectin histochemistry of equine cutaneous histiolymphocytic lymphosarcomas. Vet Pathol 1989;26(5):409-419.

[10] Sheahan BJ, Atkins GJ, Russell RJ, O'Connor JP. Histiolymphocytic lymphosarcoma in the subcutis of two horses. Vet Pathol 1980;17(2):123-33. 
[11] Tomlinson MJ, Doster AR, Wright ER. Lymphosarcoma with virus-like particles in a neonatal foal. Vet Pathol 1979;16(5);629-631.

[12] Meyer J, Delay J, Bienzie D. Clinical, laboratory, and histopathologic features of equine Iymphoma. Vet Pathol 2006;43(6):914-924.

[13] Du MQ Liu H, Diss TC, Ye H, Hamoudi RA, et al. Kaposi sarcoma-associated herpesvirus infects monotypic $(\operatorname{IgM} \lambda)$ but polyclonal naive $\mathrm{B}$ cells in Castleman disease and associated lymphoproliferative disorders. Blood 2001;97(7):2130-6.

[14] Dupin N, Diss TL, Kellam P, Tulliez M, Du MQ, et al. HHV-8 is associated with a plasmablastic variant of Castleman disease that is linked to HHV-8-positive plasmablastic Iymphoma. Blood 2000;95:1406-12.

[15] Rettig, MB, Ma HJ, Vescio RA, Pold M, Schiller G, et al. Kaposi's sarcoma-associated herpesvirus infection of bone marrow dendritic cells from multiple myeloma patients. Science $1997 ; 276(5320): 1851-4$

[16] Agius CT, Studdert MJ. Equine herpesvirus 2 and 5: Comparisons with other members of the subfamily gammaherpesvirinae. Adv Virus Res 1994;44:357-379. 
[17] Browning GF, Studdert MJ. Epidemiology of equine herpesvirus 2 (equine cytomegalovirus). J Clin Microbiol. 1987 Jan;25(1):13-6.

[18] Fortier G, Pronost S, Miszczak F, Fortier C, Léon A, et al. Identification of equid herpesvirus-5 in respiratory liquids: a retrospective study of 785 samples taken in 2006-2007. Vet J 2008;182:346-348

[19] Bell SA, Balasuriya UB, Gardner IA, Barry PA, Wilson WD, et al. Temporal detection of equine herpesvirus infections of a cohort of mares and their foals. Vet Microbiol 2006;116:249257

[20] Marenzoni ML. Age-dependent prevalence of equid herpesvirus 5 infection. Vet Res Commun. 2010 Dec;34(8):703-8.

[21] Halfdanarson TR, Markovic SN, Kalokhe U, Luppi M. A non-chemotherapy treatment of a primary effusion lymphoma: durable remission after intracavitary cidofovir in HIV negative PEL refractory to chemotherapy. Ann Oncol 2006;17(12):1849-50. 
[22] Stingaciu S, Ticchioni M, Sudaka I, Haudebourg J, Mounier N. Intracavitary cidofovir for human herpes virus-8-associated primary effusion lymphoma in an HIV-negative patient. Clin Adv Hematol Oncol 2010;8(5):367-74.

[23] Wong DM, Belgrave RL, Williams KJ, Del Piero F, Alcott CJ, et al. Multinodular pulmonary fibrosis in five horses. J Am Vet Med Assoc 2008 Mar 15;232(6):898-905.

[24] Vander Werf KA, Davis EG. Disease remission in a horse with EHV-5-associated lymphoma. J Vet Intern Med 2013 Mar-Apr;27(2):387-9. 


\begin{tabular}{|l|l|l|l|}
\hline & Type of lymphoma & IHC result & PCR result \\
\hline Horse 1 & Multicentric & T-cell rich, B-cell & Positive \\
\hline Horse 2 & Submandibular & T-cell rich, B-cell & Positive \\
\hline Horse 3 & Cutaneous & Not performed & Positive \\
\hline Horse 4 & Cutaneous & T-cell rich, B-cell & Positive \\
\hline Horse 5 & Mediastinal & Not performed & Negative \\
\hline Horse 6 & Multicentric & Not performed & Positive \\
\hline Horse 7 & Solitary tumor of extranodal site & T-cell rich, B-cell & Negative \\
\hline Horse 8 & Alimentary & T-cell & Negative \\
\hline Horse 9 & Solitary tumor of extranodal site & Non-differentiated* & Negative \\
\hline Horse 10 & Multicentric & T-cell & Positive \\
\hline Horse 11 & Multicentric & T-cell rich, B-cell & Positive \\
\hline Horse 12 & Multicentric & Non-differentiated* & Positive on pleural \\
& & & fluid, negative on \\
& & & lymph node \\
\hline
\end{tabular}

Table 1: Twelve cases of lymphoma classified by type of lymphoma, immunohistochemical staining result, and result of PCR analysis for EHV-5. ${ }^{*}$ Non-differentiated: no stain uptake. 